\title{
Oral Health and Care at Intensive Care Units
}

Alexandre Franco Miranda*

Catholic University of Brasília Brasil (HCBr), Brasilia, Brazil

*Corresponding author: Miranda AF, Coordinator and Professor, Catholic University of Brasilia (UCB) and Hospital do Coração do Brasil (HCBr), Dentistry for Special Patients, Geriatric Dentistry, Hospital and ICU Dentistry, Catholic University of Brasília (UCB), QS 07, Lote 01, EPCT - Bloco S - Águas Claras, Brasília 71966-700, Brazil, Tel: 556181369896; E-mail: alexandrefmiranda@gmail.com

Received date: November 28, 2016; Accepted date: December 27, 2016; Published date: December 30, 2016

Copyright: (C) 2016 Miranda AF. This is an open-access article distributed under the terms of the Creative Commons Attribution License, which permits unrestricted use, distribution, and reproduction in any medium, provided the original author and source are credited

\begin{abstract}
Hospitalized patients and patients treated in Intensive Care Units (ICUs) are at high risk of contracting infectious diseases, mainly lung diseases resulting from respiratory pathogens found in the oral cavity due to deficient oral health maintenance. This problem could be avoided through preventive actions that require minimum intervention. The surface of the tooth, tongue and prostheses, as well as the ICU devices in contact with the patients' mouth, is large reservoirs for pathogens. Thus, cleaning the patients' mouth and removing infection foci may positively influence the quality of life and well-being of critically ill patients. The aim of the current study is to address the importance of having dentists in the health teams working in ICUs, as well as the activities performed, the necessary dental care and the relation between oral and systemic conditions. The study was approved by the Ethics Committee of the Catholic University of Brasília, Brazil, under protocol number CAAE 44578215.0.0000.0029. It was concluded that the lack of preventive measures, as well as the deficient oral cavity hygiene and clinical care in ICUs, are risk factors for the development of systemic diseases, mainly of diseases affecting the respiratory and cardiological tracts; therefore, the participation of dental surgeons in the interdisciplinary team is crucial to promote health in hospital environments.
\end{abstract}

Keywords: Dental health service; Health care quality; Intensive care units; Oral hygiene; Quality of life; Ventilator-associated pneumonia

\section{Introduction}

Different professionals provide care to critically ill patients in Intensive Care Units (ICUs). These professionals form an interdisciplinary team of physicians, nurses, nursing technicians, physical therapists, dieticians, speech therapists, although there is little participation of dental surgeons $[1,2]$.

Multidisciplinarity concerns the gathering of knowledge and information about each health field to be applied in actions aimed at promoting health and quality of life to ICU patients [1,3].

A bill approved by the Brazilian legislative body has established the mandatory presence of dental professionals in the ICUs of public and private hospitals, as well as in hospital assistance as a whole [4].

The expertise in Hospital Dentistry was validated by the Federal Council of Dentistry in 2015, which has integrated the dental surgeon to all hospital departments (Inpatient Units, Operating Rooms and Intensive Care Units) [4-11].

This measure was taken because hospitalized patients have poor immunity and predisposition to poor oral hygiene, fact that favors the increased colonization of the oral biofilm by gram-negative organisms harmful to the patients' health. Thus, such fact may contribute, among other consequences, to the worsening of the patients' general health condition - as in the case of pneumonia acquired in hospital environments - and, consequently, to prolong hospitalization time [2,12-14].

Integrating dental care to the services provided to ICU patients is extremely important to prevent systemic complications arising from oral conditions, since these patients are more likely to have their general health worsened due to greater chances of contracting associated-systemic and/or oral infections [15-17].

The presence of biofilm and tongue coating in large quantities and its complexity, as well as the poor oral hygiene and periodontal diseases found in critically ill patients, are factors that may favor the development of severe respiratory tract infections, such as nosocomial or hospital-acquired pneumonia, which is the second largest hospitalacquired infection presenting up to $50 \%$ chance of mortality and bacterial endocarditis $[11,12,14,18]$.

These patients are also prone to therapy-related dehydration and, consequently, to xerostomia, decreased salivary flow, oral lesions, spontaneous bleeding in the oral mucosa and fissures $[1,2,10,13,19,20]$.

The aim of the current study is to address the importance and the performance of dentist in multi-professional teams working in Intensive Care Units, in order to help disclosing the specific role dental surgeons play in this environment, as well as to support the insertion of this particular health procedure in hospital sectors. The study was approved by the Ethics Committee of the Catholic University of Brasília, Brazil, CAAE number 44578215.0.0000.0029.

\section{Hospital Dentistry}

Hospital Dentistry has emerged in America in the Nineteenth century and it aimed at establishing and/or maintaining good oral health conditions in hospitalized patients in order to improve their systemic health by providing a complete therapy and improving these patients' quality of life $[1,2,7,9,11]$.

The relation between systemic and oral health has been increasingly addressed. It is currently known that several systemic diseases whether they are infectious, immunological or therapy-related show 
oral manifestations. They may also result from inadequate oral health conditions, such as poor hygiene, biofilm accumulation, periodontal diseases and tooth root remains (infection foci) [8,9,21-23].

Performing dental procedures in hospital environments is a challenge, since this area of expertise is not yet fully acknowledged and is discriminated by the health professionals themselves, who do not believe in the effective participation of dental care in the comprehensive treatment of hospitalized patients $[3,12,24,25]$.

The knowledge about the oral cavity, its characteristics and microbiota provides dental surgeons with the specific and adequate training to work in hospitalized patients' oral health promotion, education and prevention. Thus, their presence in multidisciplinary teams working in hospital care is essential, mainly with regard to oral health-related procedures and clinical interventions in general $[10,13,25,26]$.

\section{The Bill in Brazil}

The Brazilian Legislative Chamber and the Senate have approved a bill, which established the mandatory presence of dental professionals in ICUs and in public or private hospitals hosting treatment centers, since the mouth is an environment prone to be colonized by healththreatening pathogenic microorganisms $[4,8,11]$.

This particular bill argues that preventive dental procedures are inexpensive and able to effectively reduce the nosocomial pneumonia and ventilator-associated pneumonia (VAP) rates in critically ill patients, as well as to reduce hospital costs associated with prolonged hospitalizations [4,12,14-16,27-29].

\section{Dentistry in ICUs}

Dentistry in Intensive Care Units stands out due to the important role it plays in the comprehensive care provided to critically ill patients [24,25,30-32].

Critically ill patients are more predisposed to have their mouth colonized by highly pathogenic microorganisms, which may be inhaled, colonize the oropharynx and trigger a respiratory tract infection process. Other factors also predispose ICU patients to develop pneumonia, namely: the use of endotracheal tube, the deficient cleaning performed by the nursing team, as well as the complexity of the oral biofilm found on the patients' teeth and tongue and, mainly, in the ICU equipment $[12,14,18,31,33]$.

Patients subjected to mechanical ventilation, which is a common situation in ICUs, are more vulnerable to respiratory tract infections, since their natural immune barriers such as cough and expectoration are affected $[21,34,35]$.

The orotracheal intubation poses the risk of developing such type of infection, since the tube has direct access to the lower respiratory tract and allows microorganisms found in the mouth to have mechanical access to the lungs $[12,13,15,21,31,32,36-38]$.

\section{Main Health Issues Presented by ICU patients}

The oral health depends on factors such as dental biofilm, immunity and oral microbiota. The oral microbiota of healthy adult patients is predominantly composed of gram-positive microorganisms and facultative anaerobes such as Streptococcus oralis and Streptococcus sanguinis [39].
On the other hand, the microbiota of critically ill patients is composed of gram-negative microorganisms and highly-virulent strict anaerobes such as Streptococcus pneumoniae and Staphylococcus aureus, which are the potential etiologic agents of pneumonia $[16,18,19,35]$.

Some patients show pre-existing oral issues at the time they are hospitalized. Others present poor oral hygiene symptoms during hospitalization, only. The deficient hygiene of dental prostheses (Figure 1) and of the oral cavity performed by the patients themselves and/or by the nursing staff, as well as the patient's sedation state, the presence or absence of mechanical ventilation and the dietary regime are factors that directly influence the oral health of ICU patients, since they may favor biofilm accumulation, tongue coating (Figure 2), periodontal diseases (gingivitis, periodontitis) (Figure 3), tooth root remains (Figure 4), as well as opportunistic infections in the mouth due to immunosuppression and decreased salivary flow resulting from the action of the medication delivered to these patients $[5,14,17,23,40,41]$.

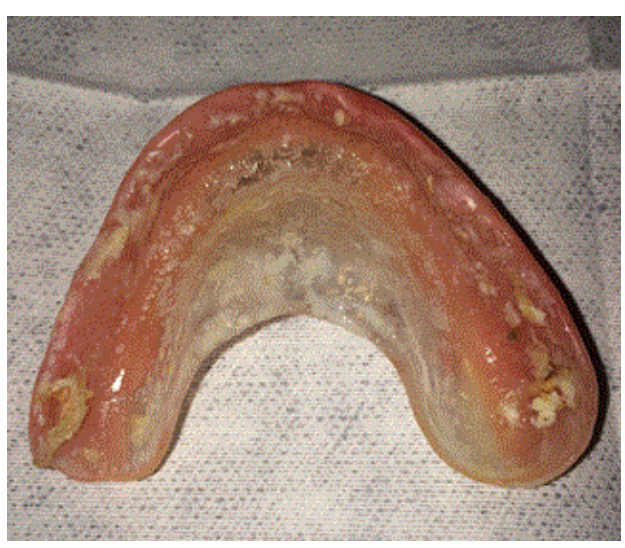

Figure 1: Poorly sanitized prosthesis of an ICU patient - there is the need of educational and sanitizing actions by the interdisciplinary team.

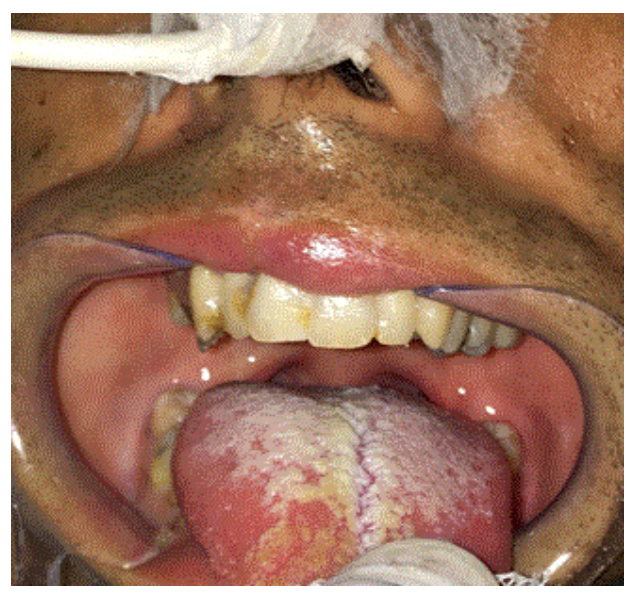

Figure 2: Patient fed through nasogastric tube presenting coating throughout his tongue - microbial reservoir of gram-negative bacteria associated with nosocomial pneumonia. 
Page 3 of 6

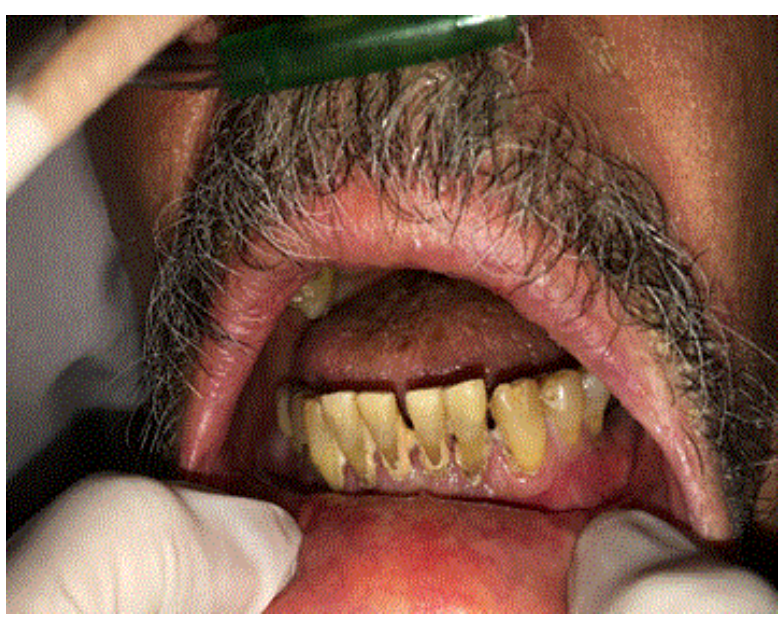

Figure 3: Supragingival calculus accumulation and tongue dorsum dryness in an ICU patient-there is the need of supragingival scaling (clinical procedure whose ethical and legal competence belongs to the dental surgeon), as well as of oral environment adaptation.

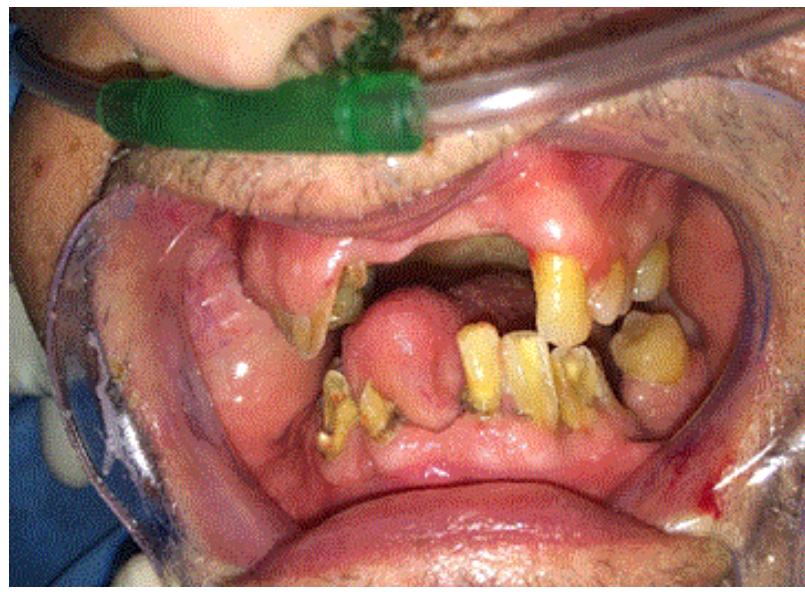

Figure 4: Oral health status of an ICU patient. Presence of tooth root remains - dental infection foci.

\section{The Management of Oral Health Promotion Activities in ICUs}

The clinical management of critically ill patients, whether they are intubated or tracheostomized, must be done along with the intensivist doctor, the physiotherapist or the nurse responsible for positioning the patient's bed at $45^{\circ}$ at the time to perform the dental procedure $[3,21,22,26,36,42]$.

The dentist surgeon must be aware of the patient's bio-psychosocial condition since it helps achieving the correct planning and performance of the demanding clinical activities. It is a way to avoid the use of interventions non-applicable to the patient's actual clinical condition and nuisance $[2,11,24,30,40,43,44]$.
The repositioning of patients and of the equipment used in ICUs must be well organized by the nursing staff because it may hinder visibility during the oral health procedure (Figure 5) and help overcoming patient's non-cooperation during the treatment $[3,16,13,35,37,44]$.

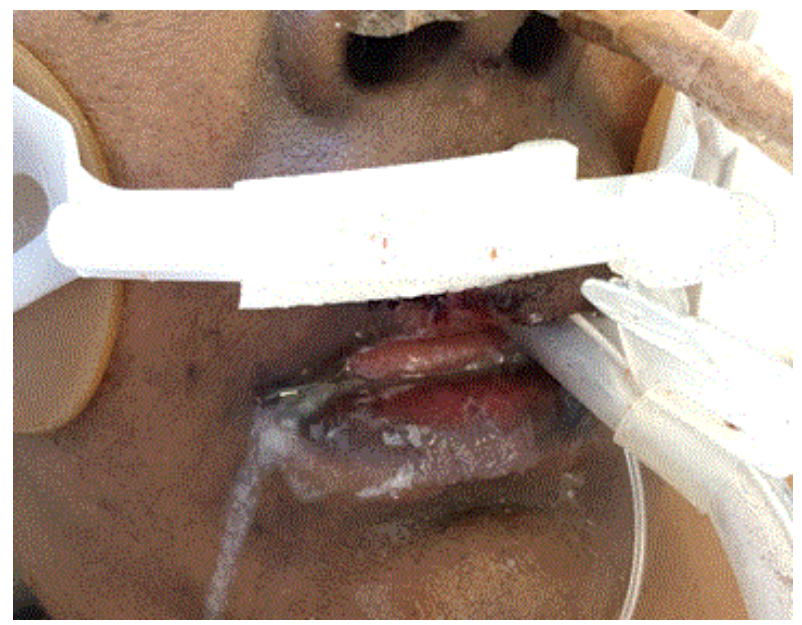

Figure 5: ICU patient subjected to orotracheal intubation and to nasogastric feeding - Difficulties in the management of and in the professional adaptation to oral hygiene procedures.

It is mandatory shutting down the nasogastric feeding of certain patients. This procedure may be carried out by the dietician or the nursing staff, because dentistry procedures might make the patient nauseous, mainly during tongue and posterior dental region cleaning $[5,30,42,45]$.

Dentists do not have the opportunity to dedicate themselves to hospital environments, mainly to ICUs; therefore, is it necessary technically and scientifically preparing these professionals in order to help them providing good oral health practices to critically ill patients $[17,25,30,40,44]$.

\section{Adapting the Oral Health Promotion Activities to ICUs}

According to clinical experience, using auxiliary means is very helpful; it means applying beneficial clinical tricks or strategies to get wider mouth opening and better visibility during oral health clinical procedures applied to intubated and tracheostomized patients $[5,17,30,46]$.

The correct use of mouth expanders and previously made mouth openers along with the teamwork of a medical staff comprising dentists, physical therapists and intensivist doctors may help better accessing the patients' mouth $[22,26,30,36,40]$.

Dental care activities must not be performed by a single professional. It is important having auxiliary personnel to assist the dentist during the performance of logistics activities related to the treatment. It is worth emphasizing the importance of having a welltrained nursing staff aware of the dentistry procedures, mainly with respect to the correct use of mouth expanders and mouth openers (Figures 6 and 7) [5,17,30]. 


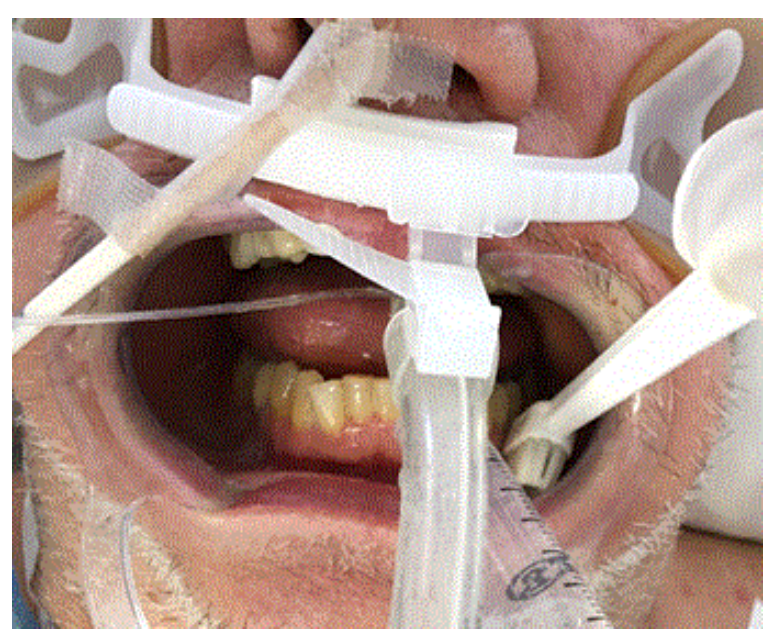

Figure 6: Professional adaptation aiming at providing increased visibility and support to preventive and oral health promotion measures applied to an intubated patient in the ICU.

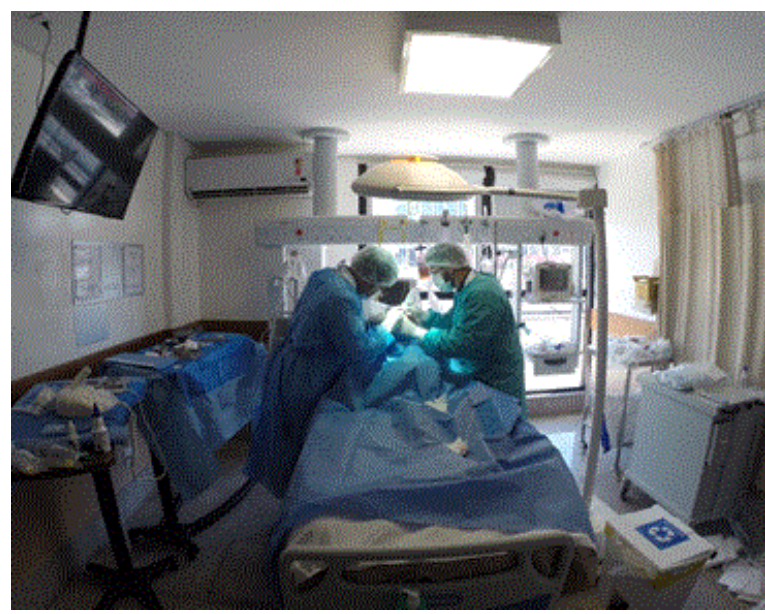

Figure 7: Full mouth disinfection - Dental procedures involving the surgical, periodontics, restorative and prevention dentistry fields performed in a single session in the ICU using intravenous sedation (constant monitoring - anesthetist/intensivist doctor) and interdisciplinary planning in order to eliminate dental infection foci, inflammation processes and pain resulting from oral issues.

The staff must be able to help with the salivary suction and to perform other oral health procedures [36].

\section{Oral X Systemic Health}

Pneumonia is the systemic disease that most correlates with oral health and it is directly linked to periodontal diseases. When it comes to ICU environments, there is high correlation between pneumonia and oral health, which is a disturbing element, since nosocomial pneumonia - an extremely debilitating infection diagnosed $48 \mathrm{~h}$ after the patient's admission to the hospital - is the second leading cause of death among hospital-acquired infections $(20-50 \%$ of the affected patients die) $[15,18,31,32,47]$.

The tongue and tooth surfaces are microbial reservoirs of high complexity, mainly in hospitalized patients, fact that makes the salivary secretion extremely pathogenic. Debilitated patients often show impaired reflexes and are predisposed to pulmonary aspiration. Thus, their mouth becomes the main gateway for microorganisms harmful to their systemic health $[14,19,27]$.

The risks increase from 6 to 21 times in the case of patients subjected to mechanical ventilation or to endotracheal tube, because the tube cuff also works as a microbial niche that allows bacteria to directly translocate to the lungs $[13,35,40]$.

\section{Dentistry Interventions in an Intensive Care Unit}

All dentistry interventions must be assisted by auxiliary personnel using the constant vacuum suction system installed in ICUs. The system must be equipped with a suction device adapted to it in order to enable a faster and more efficient procedure [32,42].

When the correct planning meets the needs of each critically ill patient, the preventive oral health interventions supposed to be done in the ICU do not differ from those performed in the doctor's office $[17,22,28,30]$.

The great difference lies on the dentist's professional experience in adapting him/herself to the new professional context $[5,17,20,26,45]$.

Daily teeth-bushing should not be forgotten in ICUs. It is necessary using prophylactic paste and a smooth bristled toothbrush to reach mouth areas, which are most difficult to be accessed. It is considered an irreplaceable measure for biofilm and bacterial plaque removal $[2,12,14,22,37,47]$.

The oral hygiene deficiency condition found in ICUs may be the greatest issue in technical dentistry, since most ICU professionals perform oral hygiene using wooden spatulas wrapped in gauze $[25,30]$.

Although this technique is widely used, it does not meet the official dental practices and shows low effectiveness in removing the bacterial plaque $[1,11,14,34]$.

It is necessary better understanding the herein discussed subject, as well as the way health professionals deal with the main techniques and with the oral health procedures assumed to favor the correct oral hygiene protocol [19,22,25,30,41].

The fluoride therapy, using $1.23 \%$ or neutral acidulated fluoride, may help the first phase of the treatment, mainly in terms of keeping the oral $\mathrm{pH}$ in ICU patients. It is important highlighting that this therapy is an oral health complementary activity and that it should be done after the oral hygiene, using the toothbrush for a certain period [5,22].

The tongue hygiene must be always preformed from the posterior to the anterior region of the mouth. The use of some auxiliary means such as tongue scrapers may be effective in eliminating the environment favorable to bacterial accumulation, specially the gramnegative bacteria, which are associated with nosocomial pneumonia $[17,20,29,36,39]$.

The tongue hygiene, in other words, the tongue coating removal must be constantly done using the patient's toothbrush humidified 
Page 5 of 6

with saline solution or with $0.12 \%$ chlorhexidine; the procedure must be supervised $[13,16,30,32,45]$.

Another efficient clinical dental procedure comprises the use of $0.12 \%$ chlorhexidine, twice a day, for at most 7 to 10 days. This medication has bactericidal and bacteriostatic properties. Thus, it helps eliminating possible inflammatory sites and bleeding, since such conditions could impair future treatments $[30,36,44,47]$.

Performing prophylaxis in the clinic using constant vacuum suction with $0.12 \%$ chlorhexidine may be efficient since the patients have difficulty in rinsing and spitting $[5,25,28,34]$.

Using hemostatic tweezers or needle holders with little amount of gauze soaked in this chlorhexidine solution - after using the herein described clinical management and adaptation - is another oral hygiene possibility for intubated and tracheostomized patients $[12,17,19,22,30,38]$.

This technique may be especially effective in the hygiene of posterior regions of the mouth and of the endotracheal tube $[29,30,36,37,41]$.

Other oral antiseptics are used in some ICUs, but only a few studies described in the literature have presented clinically effective results. It is possible seeing that the financial planning advocates for the use of the cheapest techniques rather than the more effective ones $[10,11,34,41]$.

The presence of cavities and dental fractures may result from existing caries lesions or traumas at the time the patient is hospitalized. The Atraumatic Restorative Treatment (ART) favors these conditions because the resin-modified glass-ionomer cements are the most reliable materials due to their biocompatibility and release of fluoride ions. These cements enable remineralization in early dental caries, fact that benefits the first stage of the treatment $[20,30]$.

The ART technique, the supragingival scaling and the root planning must be done by dentists, only. These specific procedures cannot be performed by other professionals, who could be ethically accounted by competent organs for performing such procedure, whenever necessary $[2,3,19,30]$.

Emergency surgical interventions may be done within the ICU environment, especially when the tooth becomes an infectious and painful site, which is considered a negative aspect to patients' rehabilitation $[11,26,28]$.

It is mandatory performing the clinical planning alongside with the intensivist doctor and all the multidisciplinary staff before the surgical intervention, since they must know the patients' real systemic conditions, as well as the possible adverse reactions to the anesthetic and post-extraction medications $[1,2,7,11,17]$.

It is expected that the clinical experience and the dentistry orientation focused on promoting health and quality of life to critically ill patients may work as possible training or future guides to hospital environment assistance, mainly in Intensive Care Units $[13,15,17,19,20,24,26,29,30,31,35,36,42]$.

Full Mouth strategy is used to oral health promotion in ICUs. All dental needs of each ICU patient were addressed in a single session, which was monitored by the physicist and by the ICU staff. Such procedure often required intravenous sedation, which was performed by the physician in charge. This particular procedure requires the dental surgeon to be prepared for the possible clinical needs of the patients, as well as to always respect their individuality and urgent needs in order to solve the oral issues that may and are affecting the systemic health of critically ill patients $[48,49]$.

\section{Interdisciplinarity in the ICU}

Dental surgeons should be assigned to the interdisciplinary teams working in intensive care units in order to teach/train the other ICU professionals and fully assist hospitalized patients, since only dental professionals have the extensive knowledge about oral hygiene techniques, the microbiota, the diseases affecting the oral cavity, as well as about specific dental procedures such as supragingival scraping, procedures belonging to fields related to dental prosthesis and dental extractions, to the clinical assessment of oral lesions, and to the resolution of issues directly affecting the stomatognathic system $[3,5,6,10,11,15]$.

Interdisciplinarity concerns the gathering of specific opinions from each specialty. It emphasizes the team approach in health care and allows the interaction and integration of all the elements involved in a health situation in order to understand the human being as a whole. It directly relates all types of science and is a determining health promotion factor concerning ICU patients $[2,17,32]$.

The oral health of patients is often neglected within treatment centers and ICUs, and such neglect may trigger serious consequences for their systemic health $[6,9,10,15]$.

It is necessary developing specific oral health promotion protocols in hospitals. It is also important having dental surgeons effectively present in this environment so that dentistry can be inserted in the hospital routine in a humane way in order to provide an integrated and comprehensive care to the patients to help them healing fast $[13,22,25,26,37,45]$.

\section{Conclusion}

The relation between oral cavity factors and systemic factors shows the need of the dental surgeons' effective participation in interdisciplinary teams working in Intensive Care Units.

Aspects such as poor oral hygiene, lack of dental clinical procedures, management and professional adaptation, as well as the oral health neglect by the patients themselves and by health professionals, pose risks to the patients' health as a whole.

The professional practice of dental surgeons in Intensive Care Units is crucial to provide quality of life, as well as differentiated health care, to critically ill patients.

\section{References}

1. Schlesener VRF, Rosa UD, Raupp SMM (2012) The care of the oral health of ICU patients. Cinergis 13: 73-77.

2. Amaral COF, Marques JA, Bovolato MC, Parizi AGS, Oliveira A, et al. (2013) Importance of the dentist in the Intensive Care Unit: multidisciplinary evaluation. Rev APCD 67: 107-111.

3. Reader TW, Mearns K, Cuthbertson (2011) Interdisciplinary communication in the intensive care unit. British J Anaesth 98: 347-352.

4. Brasil Câmara dos Deputados e Senado Federal (2013) Comissão de Assuntos Sociais. Projeto de Lei, p: 34.

5. Miranda AF, Montenegro FLB (2010) Preventive dental care in an elderly dependent patient in the Intensive Care Unit (ICU) - Case report. Rev Paul Odontol 32: 34-38. 
6. Rabelo GD, Queiroz CI, Santos PSS (2010) Dental care to the patient in intensive care unit. Arq Med Hosp Cienc Med Santa Casa São Paulo 55 67-70.

7. Costa ACO; Rezende NPM, Martins FM, Santos PSS, Gallottini MHC, et al. (2013) Hospital dentistry in the public service of the State of São Paulo. Rev APCD 67: 224-228.

8. Godoi APT, Francesco AR, Duarte A, Kem APT, Silva-Lovato CH (2009) Hospital dentistry in Brazil: An overview. Rev Odontol UNESP 38: 105-109.

9. Aranega AM, Bassi APF, Ponzoni D, Wayama MT, Esteves JC, et al. (2012) What is the importance of Hospital Dentistry? Rev Bras Odontol 69: 90-93.

10. Sousa LVS, Pereira AFV, Silva NBS (2014) The performance of the dentist in hospital care. Rev Ciências da Saúde 16: 39-45.

11. Gomes SF, Esteves MCL (2012) Performance of the dentist at the ICU: A new paradigm. Rev Bras Odontol 69: 67-70.

12. Par M, Badovinac A, Plancak (2014) Oral hygiene is an important factor for prevention of ventilator-associated pneumonia. Acta Clin Croat 53: 72-78.

13. Belissimo-Rodrigues WT, Menequeti MG, Gaspar GG, Nicolini EA, Auxiliadora-Martins M, et al. (2014) Effectiveness of a dental care intervention in the prevention of lower respiratory tract nosocomial infections among intensive care patients: a randomized clinical trial. Infect Control Hosp Epidemiol 35:1342-1348.

14. Barnes CM (2014) Dental hygiene intervention to prevent nosocomial pneumonias. J Evid Based Dent Pract 14 Suppl: 103-114.

15. Azarpazhooh A, Leake JL (2006) Systematic review of the association between respiratory diseases and oral health. J Periodontol 77: 1465-1482.

16. Margo AH, Armola R (2009) Effect of oral care on bacterial colonization and ventilator-associated pneumonia. Am J Crit Care 18: 275-278.

17. Miranda AF, Lia EN, De Carvalho TM, Piau CGBC, Costa PP, et al (2016) Oral health promotion in patients with chronic renal failure admitted in Intensive Care Unit. Clin Case Rep 4: 26-31.

18. Amaral SM, Cortês Ade Q, Pires FR (2009) Nosocomial pneumonia: importance of the oral environment. J Bras Pneumol 35: 1116-1124.

19. Munro CL, Grap MJ (2004) Oral health and care in the intensive care unit: State of the science. Am J Crit Care 13: 25-33.

20. Dantas BO, De Araújo IA, De Araújo HBN, De Araújo EC, Bezerra ACB, et al (2015). Oral health and care in the intensive care unit. Rev Odontol Planal Cent 5: 28-32.

21. Brazilian Society of Pneumology and Tisiology (2007) Brazilian guidelines for the treatment of hospital-acquired pneumonia and those associated with mechanical ventilation in 2007. J Bras Pneumol 33: S1S30.

22. Ames NJ, Sulima P, Tates JM, McCullagh L, Gollins SL, et al. (2011) A review of documented oral care practices in an intensive care unit. Clin Nurs Res 20: 181-196.

23. Somal J, Darby JM (2006) Gingival and plaque decontamination: Can we take a bite out of VAP? J Crit Care 10: 310-312.

24. Araújo RJG, Castro CNM, Miranda TR, Melo ASM (2012) Intensivist training for oral care actions in intensive care units. Rev Bras Odontol Militar 29: 19-23.

25. Miranda AF, De Paula RM, De Castro Piau CG, Costa PP, Bezerra AC (2016) Oral care practices for patients in intensive care units: A pilot survey. Indian J Crit Care Med 20: 267-273.

26. Nelson JE, Bassett R, Boss RD, Brasel KJ, Campbell ML, et al. (2010) Models for structuring a clinical initiative to enhance palliative care in the intensive care unit: A report from the IPAL-ICU. Project (improving palliative care in the ICU). Crit Care Med 38: 1765-1772.

27. Pobo A, Lisboa T, Rodriguez A, Sole R, Magret M, et al. (2009) A randomized trial of dental brushing for preventive ventilator associated pneumonia. Chest 136: 433-439.
28. Rello J, Koulenti D, Blot S, Sierra R, Diaz E, et al. (2007) Oral care practices in intensive care units: A survey of 59 European ICUs. Intensive Care Med 33: 1066-1070.

29. Scannapieco FA, Bush RB, Paju S (2003) Associations between periodontal disease and risk for nosocomial bacterial pneumonia and chronic obstructive pulmonary disease: A systematic review. Ann Periodontol 8: 54-69.

30. Miranda AF, De Araújo IA, De Araújo HBN, De Araújo EC, Bezerra ACB (2015) Oral health promotion in intensive care unit patients: Management and adaptations. Glo Adv Res J Med Med Sci 4: 509-513.

31. Vilela MC, Ferreira GZ, Santos PS, Rezende NP (2015) Oral care and nosocomial pneumonia: A systematic review. Einstein (Sao Paulo) 13: 290-296.

32. Abidia RF (2007) Oral care in the intensive care unit: A review. J Contemp Dent Pract 8: 76-82.

33. Berry AM, Davidson PM, Masters J, Rolls K (2007) Systematic literature review of oral hygiene practices for intensive care patients receiving mechanical ventilation. Am J Crit Care 16: 552-562.

34. Muscedere J, Dodek P, Keenan S, Fowler R, Cook D, Heyland D (2008) Comprehensive evidence-based clinical practice guidelines for ventilatorassociated pneumonia: Prevention. J Crit Care 23:126-137.

35. Fields LB (2008) Oral care intervention to reduce incidence of ventilatorassociated pneumonia in the neurologic intensive care unit. J Neurosci Nurs 40: 291-298.

36. Tablan OC, Anderson LJ, Besser R (2004) Guidelines for preventing healthcare associated pneumonia, 2003: Recommendations of CDD and the Healthcare Infection Control Practices Advisory Committee. Morbidity and mortality weekly report. Recommendations and Reports 53:1-36.

37. Shi Z, Xie H, Wang P, Zhang Q, Wu Y, et al. (2013) Oral hygiene care for critically ill patients to prevent ventilator-associated pneumonia. Cochrane Database Syst 8: CD008367.

38. Prendergast V, Hallberg IR, Jahnke H, Kleiman C, Hagel P (2009) Oral health, ventilator-associated pneumonia and intracranial pressure in intubated patients in a neuroscience intensive care unit. Am J Crit Care 18: 368-376.

39. Oliveira LC, Carneiro PP, Fischer RG, Tinoco EM (2007) Presence of respiratory pathogens in the oral biofilm of patients with nosocomial pneumonia. Rev Bras Ter Intensiva 19: 428-433.

40. Jones H (2005) Oral care in intensive care units: A literature review. Spec Care Dentist 25: 6-11.

41. Paju S, Scannapieco FA (2007) Oral biofilms, periodontitis and pulmonary infections. Oral Dis 13: 508-512.

42. Yusuf H (2013) Toothbrushing may reduce ventilator-associated pneumonia. Evid Based Dent 14: 89-90.

43. Allen Furr L, Binkley CJ, McCurren C, Carrico R (2004) Factors affecting quality of oral care in intensive care units. J Adv Nurs 48: 454-462.

44. Tark G, Kocaal Galer E, Eayer I, Khorshid L (2012) Oral care practices of intensive care nurses: A descriptive study. Int J Nurs Pract 18: 347-353.

45. Feider LL, Mitchell P, Bridges E (2010) Oral care practices for orally intubated critically ill adults. Am J Crit Care 19: 175-183.

46. Porto AN, Segundo AS, Borges AH, Semenoff TADV, Miranda FP (2010) Hospital dentistry: A proposal of new discipline. RSBO 9: 119-122.

47. Pineda LA, Saliba RG, El Solh A (2006) Effect of oral decontamination with chlorhexidine on the incidence of nosocomial pneumonia: A metaanalysis. Crit Care 10: 1-6.

48. Fang H, Han M, Li Q, Cao CY, Xia R, et al. (2016) Comparison of fullmouth desinfection and quadrante-wise scaling in the treatment of adulto chronic periodontitis: A systematic review and meta-analysis. J Periodontol Research 51: 417-430.

49. Eberhard J (2016) Full-mouth treatment modalities (within 24 hours) for chronic periodontitis in adults. Evid Based Dent 17: 23-24. 